\title{
The Pharmacokinetic Study of Aspirin, Paracetamol and Naproxen with Magnesium Sulfate
}

Shah Amran ${ }^{1 *}$, Sabiha Ferdowsy Koly ${ }^{1}$, Sangita Paul Kundu ${ }^{1}$, Abu Asad Chowdhury ${ }^{1}$, Amjad Hossain ${ }^{1}$, Zakir Sultan ${ }^{2}$, Asma Rahman ${ }^{2}$, Sagar Kumar $\mathrm{Paul}^{3}$, Satabdi Shikder ${ }^{3}$, Tasneem Nayla Mredula ${ }^{3}$ and Shampa Kundu ${ }^{4}$

${ }^{1}$ Department of Pharmaceutical Chemistry, Faculty of Pharmacy, University of Dhaka, Dhaka-1000, Bangladesh

${ }^{2}$ Centre for Advanced Research in Sciences, University of Dhaka, Dhaka-1000, Bangladesh

${ }^{3}$ Department of Pharmacy, State University of Bangladesh, Dhanmondhi, Dhaka-1205, Bangladesh

${ }^{4}$ Department of Pharmacy, Bangladesh University, Mohammadpur, Dhaka-1207, Bangladesh

\begin{abstract}
The present study was designed to evaluate the bioavailability of single drug as well as drug with $\mathrm{Mg}(\mathrm{II})$ complexes in the systemic circulation of rats. 132 healthy rats were selected for this study. The rats were fasted for 12 hours (overnight) prior to drug administration and kept fasting up to blood collection after administration of the drugs. The rats were divided in to three groups for each drug of study: control (rats without giving any drugs for each analysis) and group 1 for reference (single drug) and group 2 for test drug i.e. drug-Mg complexes. In this study both the test (drug-Mg complex) drug and corresponding reference drug were administered at the dose of aspirin at 10 $\mathrm{mg} / \mathrm{kg}$ body weight, paracetamol at $16 \mathrm{mg} / \mathrm{kg}$ body weight and naproxen at $16 \mathrm{mg} / \mathrm{kg}$ body weight in the solution form through oral route. From the pharmacokinetic study, it was found that concomitant administration of magnesium with aspirin slightly increased elimination rate and lowered the bioavailability than the reference aspirin. When magnesiun was concomitantly administered with paracetamol, it markedly increased elimination rate and decreased the bioavailability than that of the reference paracetamol. When magnesiun was concomitantly administered with naproxen, it decreased elimination rate and remained in the systemic circulation for longer time.
\end{abstract}

Keywords: Complexation; Aspirin; Paracetamol; Naproxen; Magnesium sulfate; Pharmacokinetic

\section{Introduction}

The biological action of the drug-metal complexes may affect stability and usual therapeutic activities of drugs through changing pharmacokinetic and pharmacodynamic parameters. There are many organometallic compounds which have remarkable pharmacological effects and are used as active ingredients. Magnesium is present in three different states in most biological system: freely coordinated to water, associated with anions and bound to protein. On average, the human body contains approximately $24 \mathrm{~g}$ of magnesium. Few other drugs have been tested for as many roles as magnesium- based drugs have [1]. The second most abundant intracellular cation is magnesium $\left(\mathrm{Mg}^{++}\right)$which has several critically important roles in the body. In addition to the energy production through adenosine triphosphate (ATP), maintenance of serum sodium, calcium, potassium, smooth muscles tone in the vessel wall, magnesium is essential for normal neuromuscular function and $\mathrm{Ca}^{++}$and $\mathrm{K}^{+}$transport across the plasma membrane [2]. Magnesium deficiency in the body is associated with different risk factors for cardiovascular diseases and atherogenesis, such as increasing oxidative stress, cytokine synthesis, synthesis of nitric oxide and mediators of inflammation, and adhesion molecules on microvascular endothelial cells [3].

The proposed curative properties of $\mathrm{Mg}$-based non-steroidal anti-inflammatory drugs (NSAIDs) might lead to the development of some $\mathrm{Mg}$ (II) complexes of NSAIDs with enhanced anti-inflammatory activity and reduced gastrointestinal toxicity compared with the parent drug. For this reason, complexation of aspirin, paracetamol and naproxen with metal ions is an interesting field of research.

Most NSAIDs are weak organic acids that are well absorbed after oral administration. However, food can impair the oral absorption of some NSAIDs (e.g., phenylbutazone, meclofenamate, flunixin and robenacoxib). Several NSAIDs are available as parenteral formulations for intravenous, intramuscular and subcutaneous administration. Some parenteral formulations are highly alkaline (e.g., phenylbutazone) and may cause tissue necrosis if injected perivascularly. Once absorbed, most NSAIDs are extensively (up to 99\%) bound to plasma proteins, with only a small proportion of unbound drug available to be active in the tissues. NSAIDs may also compete for binding sites with other highly proteinbound compounds, leading to some drug displacement; however, this displacement has little therapeutic consequence because it does not affect the concentration of the free drug. Because NSAIDs are highly protein bound and extravasation of protein occurs in inflammation, NSAIDs tend to concentrate in areas of inflammation. Consequently, their duration of action typically exceeds that predicted by elimination half-life [4]. Aspirin is absorbed rapidly from the stomach and intestine by passive diffusion. Salicylate distributes rapidly into the body fluid compartments. It binds to albumin in the plasma [5]. Paracetamol is well absorbed in the gastrointestinal tract. Oral bioavailability is dose dependant. Paracetamol is distributed throughout the body fluids in a homogeneous way [5]. Naproxen is readily absorbed from the gastrointestinal tract. Peak plasma concentrations are attained 2-4 hours after ingestion. Naproxen is absorbed from the gastrointestinal tract with an in vivo bioavailability of $95 \%$. Naproxen is highly bound to plasma protein, accounting for about $99.6 \%$ at a total plasma level of $23-40 \mu \mathrm{g} / \mathrm{mL}$ [6]. The aim of the present work was to observe the

*Corresponding author: Md Shah Amran, Professor, Department of Pharmaceutical Chemistry Faculty of Pharmacy, University of Dhaka, Dhaka-1000, Bangladesh, Tel: +8801718617915; Fax: +88029667222; E-mail: amranms@du.ac.bd

Received December 08, 2015; Accepted May 15, 2015; Published May 22, 2015

Citation: Amran S, Koly SF, Kundu SP, Chowdhury AA, Hossain A, et al. (2015) The Pharmacokinetic Study of Aspirin, Paracetamol and Naproxen with Magnesium Sulfate. Pharm Anal Acta 6: 372. doi:10.4172/21532435.1000372

Copyright: $\odot 2015$ Amran S, et al. This is an open-access article distributed under the terms of the Creative Commons Attribution License, which permits unrestricted use, distribution, and reproduction in any medium, provided the original author and source are credited. 
pharmacokinetic profile and bioavailability of the drugs and drug with $\mathrm{Mg}(\mathrm{II})$ complexes in the systemic circulation of rat through area under curve (AUC) calculation. The anti-inflammatory activities and any possible toxic effect of the metal $(\mathrm{Mg})$ complexes with these drugs were also studied.

\section{Materials and Methods}

\section{Materials}

Aspirin and paracetamol were collected from Square Pharmaceuticals Ltd., Dhaka, Bangladesh; naproxen was collected from SK+F Pharmaceuticals Ltd., Dhaka, Bangladesh. Magnesium sulfate heptahydrate (E. Merk, India, Ltd.), Methanol (Active Fine Chemicals Ltd., Dhaka, Bangladesh), Demineralized water and other reagents were supplied from laboratory.

\section{Instruments}

Centrifuge Machine, HPLC (Shimadzu, Japan).

\section{Experimental animal}

Young Swiss-albino rats, average weight range 240-260 g were used for the experiment. The rats were purchased from the animal house of the Department of Pharmacy, Jahangirnagar University, Savar, Dhaka, Bangladesh. They were kept in standard environmental conditions in the Animal House, Institute of Food and Nutrition Sciences (IFNS), University of Dhaka, Bangladesh for one week for adaptation after their purchase and fed ICDDR, B formulated rodent food and water ad libitum. The experiment was carried out in the Department of Pharmacy, State University of Bangladesh, Dhanmondi, Dhaka, Bangladesh.

\section{Method}

The Pharmacokinetic analysis was carried out in the Department of Pharmaceutical Chemistry, University of Dhaka, Bangladesh by measuring AUC for blood samples of the reference as well as the test animals in case of each of the pure drug as well as the drug- $\mathrm{Mg}$ complexes.

\section{Pharmacokinetic measures of systemic exposure [7]}

Systemic exposure means comparable rate and extent of absorption. Exposure measures are defined relative to early, peak and total portions of the serum concentration- time profile, as follows:

For single-dose studies, the measurement of total exposure should be:

a) Area under the serum concentration-time curve from time zero to time $\mathrm{t}\left(\mathrm{AUC}_{0-\mathrm{f}}\right)$, where $\mathrm{t}$ is the last time point with measureable concentration for individual formulation.

b) Area under the serum concentration-time curve from time zero to infinity $\left(\mathrm{AUC}_{0-\mathrm{a}}\right)$, where $\mathrm{AUC}_{0-\alpha}=\mathrm{AUC}_{0-\mathrm{t}}+\mathrm{C}_{\mathrm{t}} / \lambda_{z}, \mathrm{C}_{\mathrm{t}}$ is the last measurable drug concentration and $\lambda_{\mathrm{z}}$ is the elimination rate constant.

\section{Study design}

The design of a pharmacokinetic study is dependent upon the drugs, dosage forms, animals used, test samples and study objectives. In this study both the test and reference drug formulations were administered at the same dose of parent drug in the solution form by the oral route. The rats were fasted for 12 hours (overnight) prior to drug administration and kept fasting up to blood collection. The rats were divided into three groups having five rats in each group for each drug of study: control (rats without giving any drugs for each analysis) and group 1 for reference (single) drug and group 2 for test sample (drug$\mathrm{Mg}$ complexes). The amount of dose was given to the rat by considering average body weight 240-260 g. The dose of drug (both reference and test) was given in a specific time interval. After collection of blood, they were centrifuged and serums were collected and preserved in vials at $4^{\circ} \mathrm{C}$. Then the concentrations $(\mu \mathrm{g} / \mathrm{mL})$ of drug and drug-Mg complexes in serum were analyzed by HPLC.

\section{Dosage and drug administration}

All the drugs were used in the solution form. Aspirin (both test and reference drugs) at a dose of $10 \mathrm{mg} / \mathrm{kg}$ body weight, paracetamol (both test and reference drugs) at a dose of $16 \mathrm{mg} / \mathrm{kg}$ body weight and naproxen (both test and reference drugs) at a dose of $16 \mathrm{mg} / \mathrm{kg}$ body weight were administered to the rats of specific group by oral route. Drug-Mg complexes were administered concomitantly at a dose of 10 $\mathrm{mg} / \mathrm{kg}$ in the rats of specific group (group 2) by oral route.

\section{Biological sampling schedule}

For aspirin: After ingestion of drug, blood samples were collected from rat into a serum tube (red color clot activator, made in Becton, Dickinson and company, New Jersey, USA) at the time intervals of 0 , $15,30,60,120,180$ and 240 minute, respectively.

For paracetamol: After ingestion of drug, blood samples were collected from rat into a serum tube at the time intervals of $0,30,60$, 120,180 and 300 minute, respectively.

For naproxen: After ingestion of drug, blood samples were collected from rat in to a serum tube at the time intervals of $0,30,60$, $120,240,360$ and 480 minute, respectively.

\section{Collection of Blood and Preparation of Evaluation Sample [8].}

Blood was collected (i.v. only) from the treated rat and $0.7 \mathrm{~mL}$ of blood was transferred in to a tube. The anti-coagulated blood sample was transferred into a $1.5 \mathrm{~mL}$ eppendorf tube (VWR International, USA) and the tubes were centrifuged at $4000 \mathrm{rpm}$ for at least 20 minute for the separation of serum. $250 \mu \mathrm{L}$ serum was taken by micropipette into another eppendorf tube. The serum was diluted by $150 \mu \mathrm{L}$ of methanol for denaturation of protein and $600 \mu \mathrm{L}$ of ethanol for deproteinization. Then the samples were made ready for HPLC analysis or preserved immediately in refrigerator until analysis.

\section{Statistical analysis}

Statistical analysis was based on the guidelines for statistics and modified for the study of in vitro and in vivo trials [9-11]. The results were expressed as mean \pm SD. Differences in mean values between experimental groups (in vitro and in vivo) were analyzed by one way analysis of variance (ANOVA), followed by Dunnett's multiple comparison tests where applicable. A 'p' value of 0.05 was taken as significant.

\section{Results}

Since the drugs are readily absorbed from the gastrointestinal tract in the systemic circulation, after ingestion of drugs, blood was collected from rat into a serum tubes at the time intervals of $0,15,30,60,120$, 180 and 240 minute, respectively for aspirin; $0,30,60,120,180$ and 300 minute, respectively for paracetamol; and 0, 30, 60, 120, 240, 360 and 
480 minute, respectively for naproxen. The drug levels in serum were analyzed by HPLC and the chromatograms are shown in the Figures $1-3$.

In HPLC chromatograms the retention times of the aspirin, paracetamol and naproxen were obtained as 7.54, 4.68, 9.77 minute, respectively where as that of for $\mathrm{Mg}$-complexes were found as 7.58, 4.67, 9.46 minute, respectively. Although the slight deviation of retention times are within the acceptable range but actually these occurred due to the complexation with magnesium.

\section{Calculation of $\mathrm{t}_{\text {max }}, \mathrm{C}_{\max }$ and AUC for aspirin}

The most important measurement of bioavailability is AUC. AUC was calculated directly from $\mathrm{C}_{\mathrm{p}}$ vs time data. The simplest, most common approach, a numerical approximation method called the trapezoidal rule was employed. The AUC of each segment was calculated as trapezoids. The area of each segment was also calculated by multiplying the average concentration by the segment width.

Aspirin (both test and reference) was administered orally to rat at a dose of $10 \mathrm{mg} / \mathrm{kg}$ body weight. The drug concentration in serum was determined at $0,15,30,60,120,180$ and 240 minute, respectively. In both (test and reference aspirin) cases, the $t_{\max }$ was found at $15 \mathrm{~min}$ and $\mathrm{C}_{\max }$ for test and reference aspirin were found to be $11.24 \pm 0.08$ and $11.39 \pm 0.06 \mu \mathrm{g} / \mathrm{mL}$, respectively. Upon plotting the mean concentration vs time interval of both test and reference aspirin the following curve was obtained (Figure 4).

The mean $\mathrm{C}_{\text {max }}$ and AUC for aspirin were calculated by extrapolation of data based on curve and are shown in Table 1.

\section{Calculation of $\mathrm{t}_{\text {max }}, \mathrm{C}_{\max }$ and AUC for paracetamol}

Paracetamol (both test and reference) was administered orally into rats at a dose of $16 \mathrm{mg} / \mathrm{kg}$ body weight. The drug concentration in serum was determined at $0,30,60,120,180$, and 300 minute, respectively. In both (test and reference paracetamol) cases, the $t_{\max }$ was found at 60 min. and $\mathrm{C}_{\max }$ of test and reference paracetamol were $3.09 \pm 0.30$ and $4.39 \pm 0.34 \mu \mathrm{g} / \mathrm{mL}$, respectively. Upon plotting the mean concentration vs time interval of both test and reference paracetamol the following curve was obtained (Figure 5).

The mean $\mathrm{C}_{\max }$ and AUC for paracetamol were calculated by extrapolation of data based on curve and is shown in Table 2.
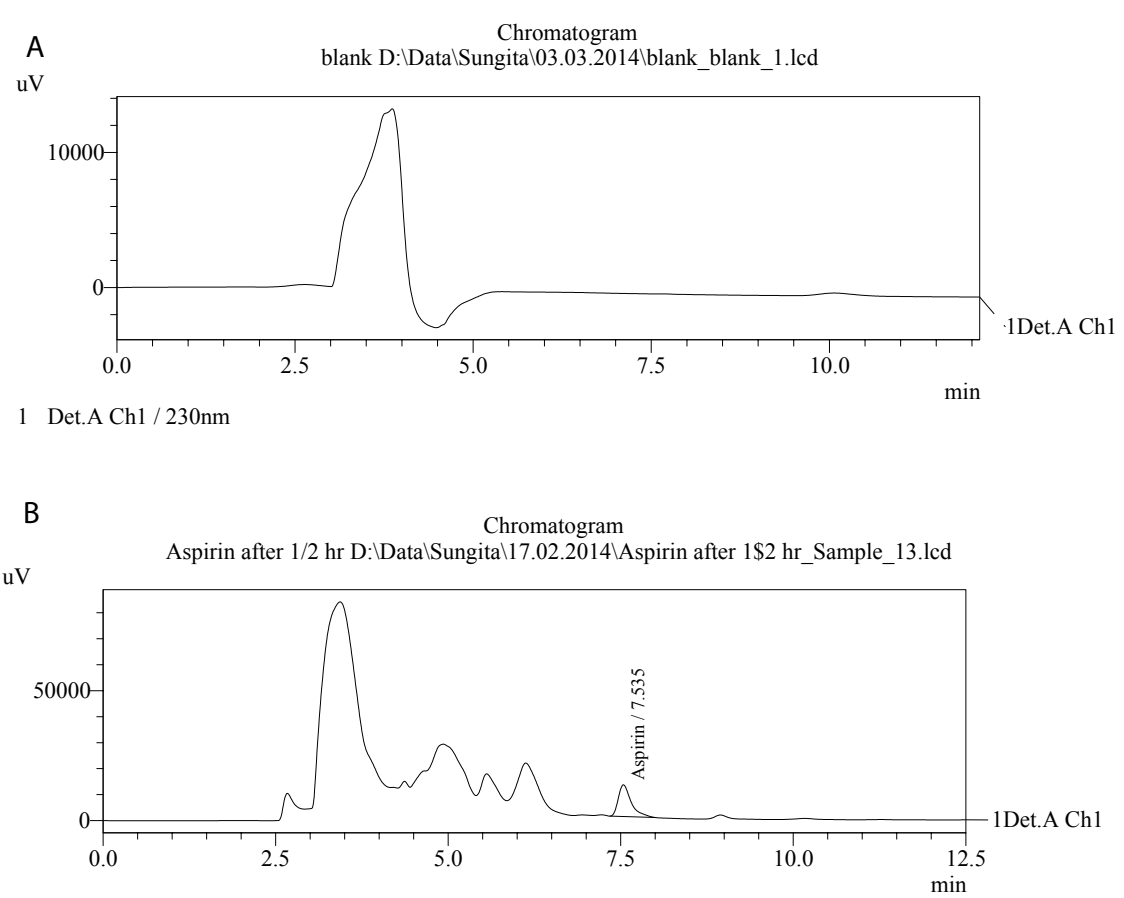

1 Det.A Ch1 / 230nm

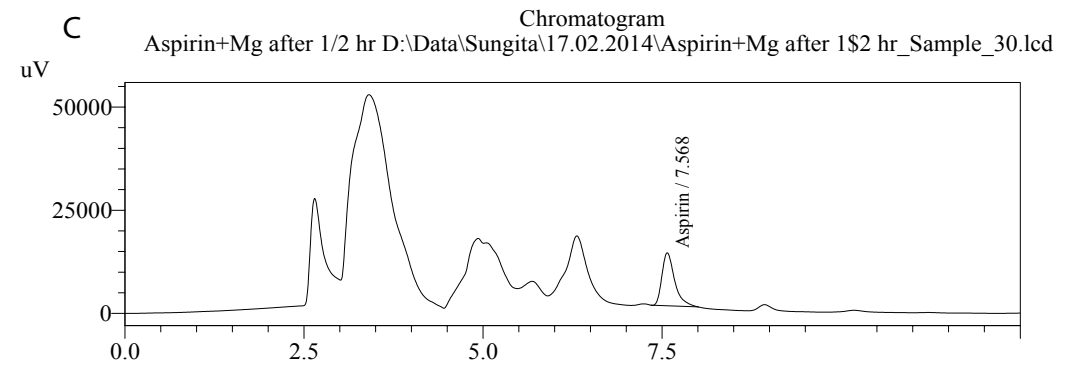

1 Det.A Ch1 / 230nm

Figure 1: Chromatograms of serum (a), aspirin in serum (as reference) (b), aspirin with MgSO4 (c). 


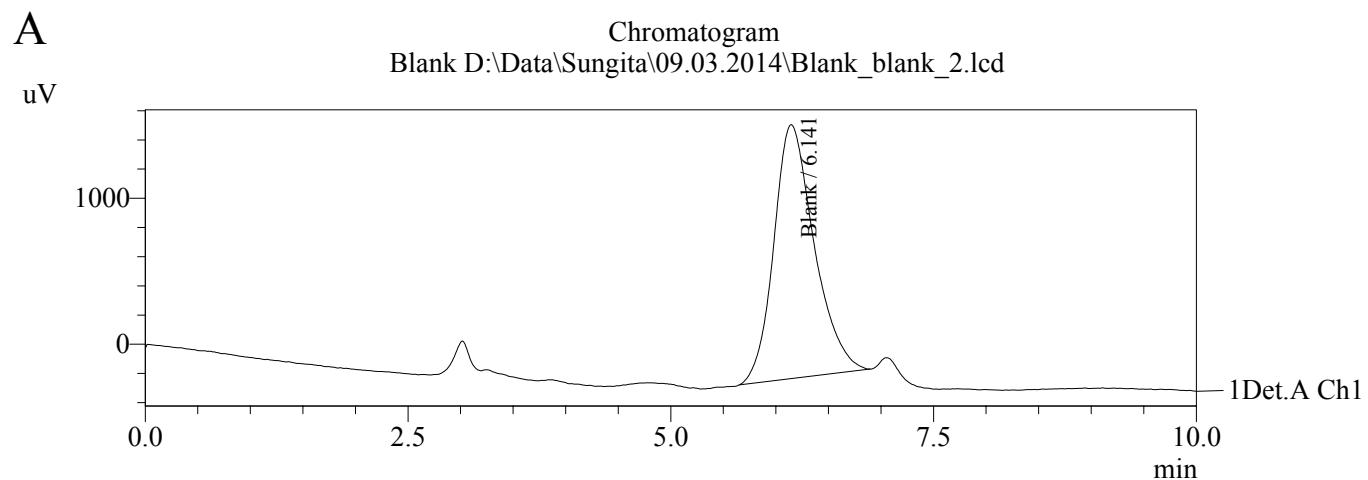

1 Det.A Ch1 / 243nm

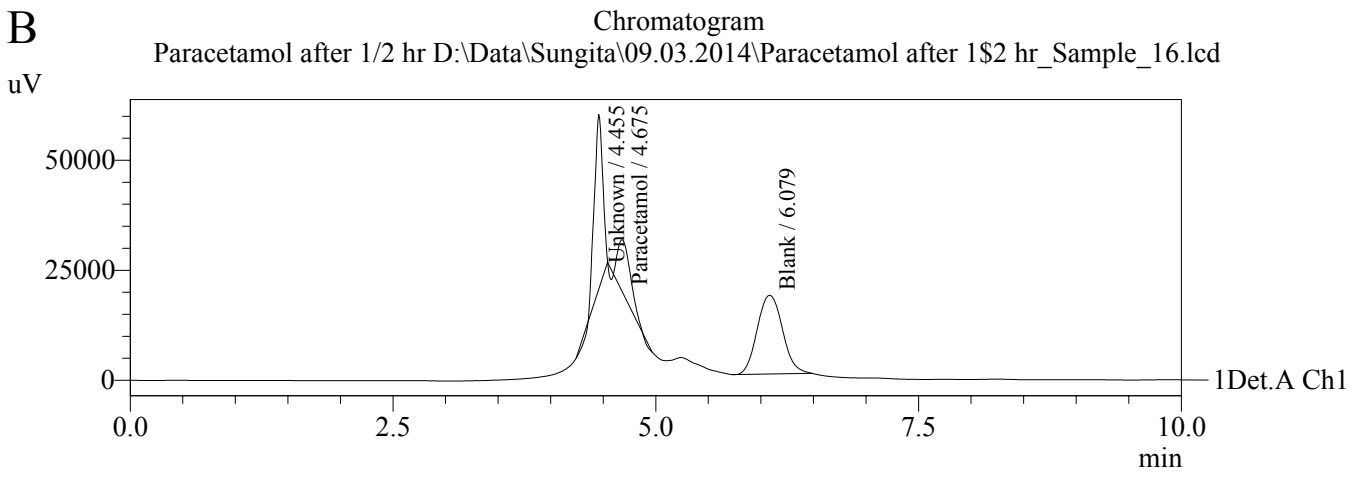

1 Det.A Ch1 / 243nm

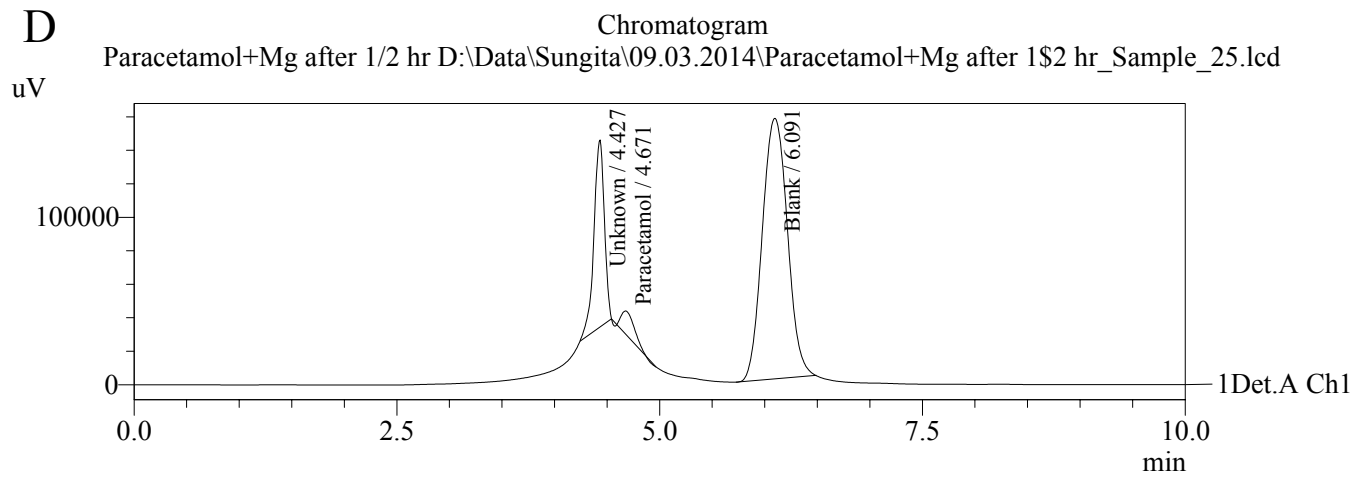

1 Det.A Ch1 / 243nm

Figure 2: Chromatograms of serum (blank) (a), paracetamol in serum (as reference) (b), paracetamol with MgSO4 (c)

\section{Calculation of $\mathrm{t}_{\max }, \mathrm{C}_{\max }$ and AUC of naproxen}

Naproxen (both test and reference) was administered orally to rat at a dose of $16 \mathrm{mg} / \mathrm{kg}$ body weight. The drug concentration in serum was determined at $0,30,60,120,240,360$ and 480 minute, respectively. In both (test and reference) cases, the $\mathrm{t}_{\max }$ of naproxen was found to be $120 \mathrm{~min}$. and $\mathrm{C}_{\max }$ of naproxen was $25.22 \pm 0.24$ and $26.49 \pm 0.35$ $\mu \mathrm{g} / \mathrm{mL}$ for test and reference, respectively. Upon plotting the mean concentration vs time interval of both test and reference naproxen the following curve is obtained (Figure 6). The mean $\mathrm{C}_{\max }$ and AUC for naproxen were calculated by extrapolation of data based on curve and is shown in Table 3.

\section{Discussion}

Aspirin is used in the treatment of mild to moderate pain, inflammation and fever. It is also used as an antiplatelet agent to prevent myocardial infarction, stroke and transient ischemic episodes. Aspirin is absorbed rapidly from the stomach and intestine by passive diffusion. Actually aspirin is transformed into salicylate in the stomach, in the intestinal mucosa, in the blood and mainly in the liver. Salicylate is the active metabolite responsible for most anti-inflammatory and analgesic effects but acetylsalicylate is the active moiety for the antiplatelet-aggregating effect. Salicylate distributes rapidly into the body fluid compartments. It binds to albumin in the plasma. With 
A

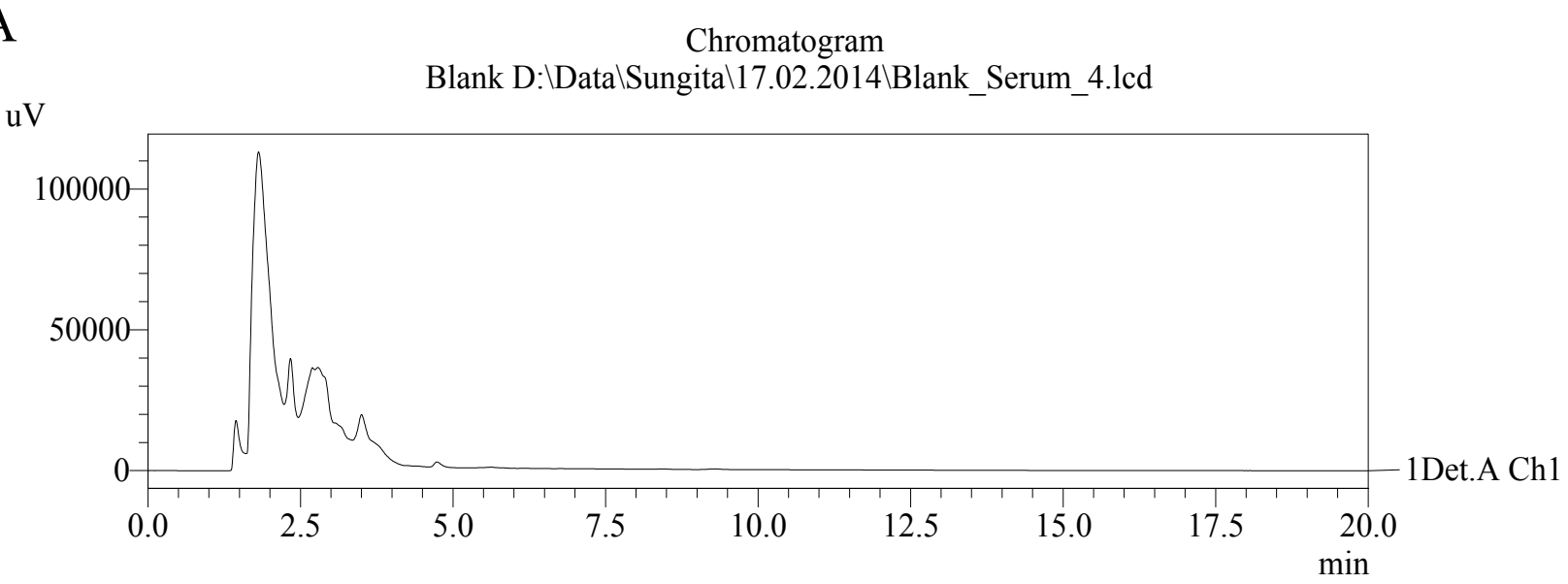

1 Det.A Ch1 / 230nm

B

$\mathrm{uV}$

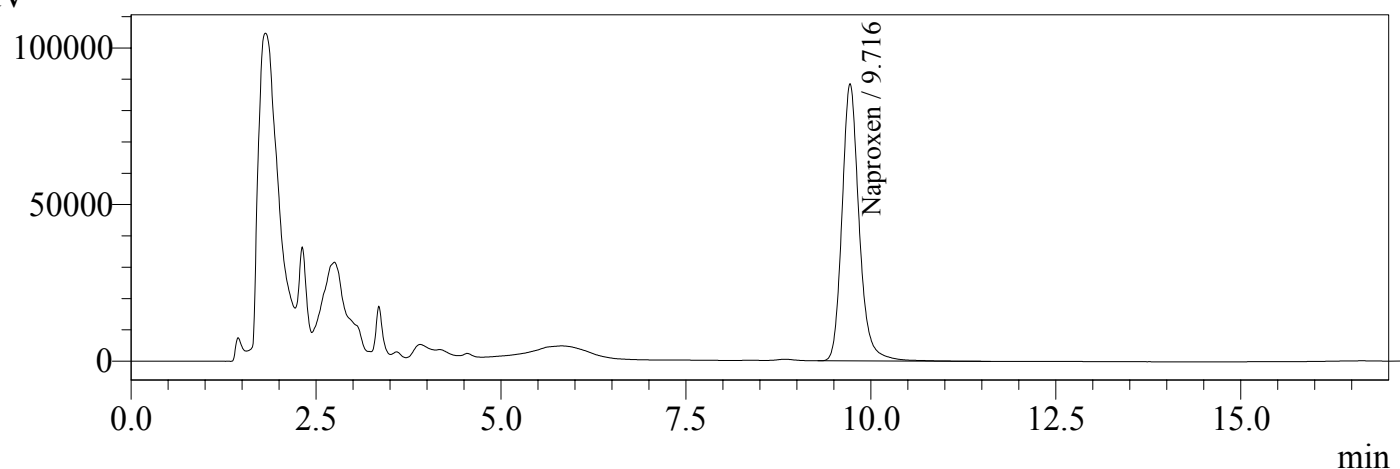

1 Det.A Ch1 / 230nm

C $\mathrm{uV}$ $\mathrm{NP}+\mathrm{Mg}$ after 1/2 hr D: $\backslash$ Data $\backslash$ Sungita $\backslash 17.02 .2014 \backslash \mathrm{NP}+\mathrm{Mg}$ after $1 \$ 2 \mathrm{hr}$ Sample 34.lcd

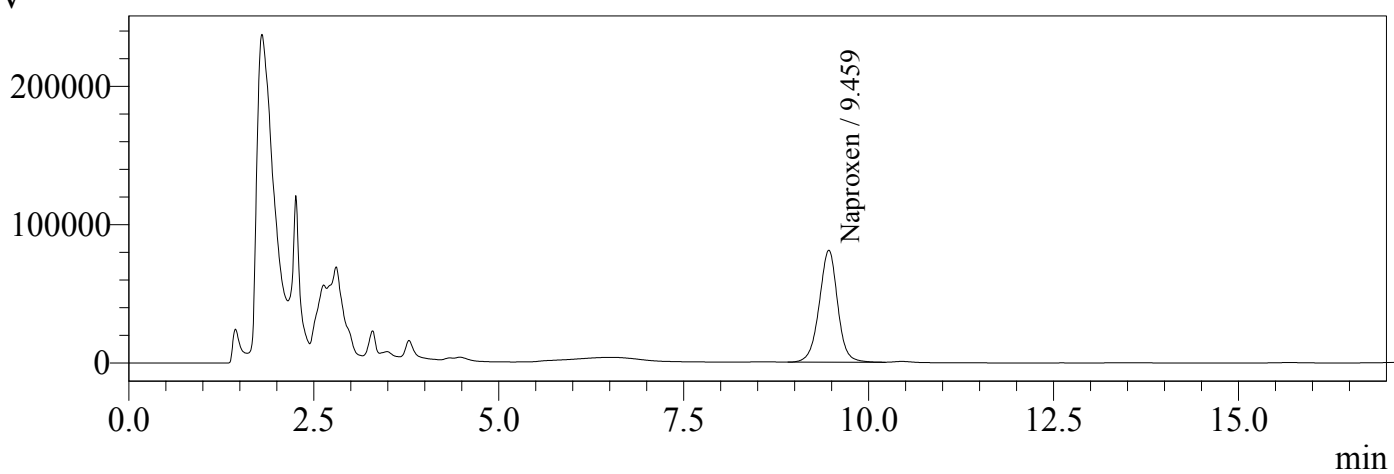

1Det.A Ch1

1Det.A Ch1 $\min$

1 Det.A Ch1 / 230nm

Figure 3: Chromatograms of serum (blank) (a), naproxen (as reference) (b), naproxen with MgSO4 (c). 


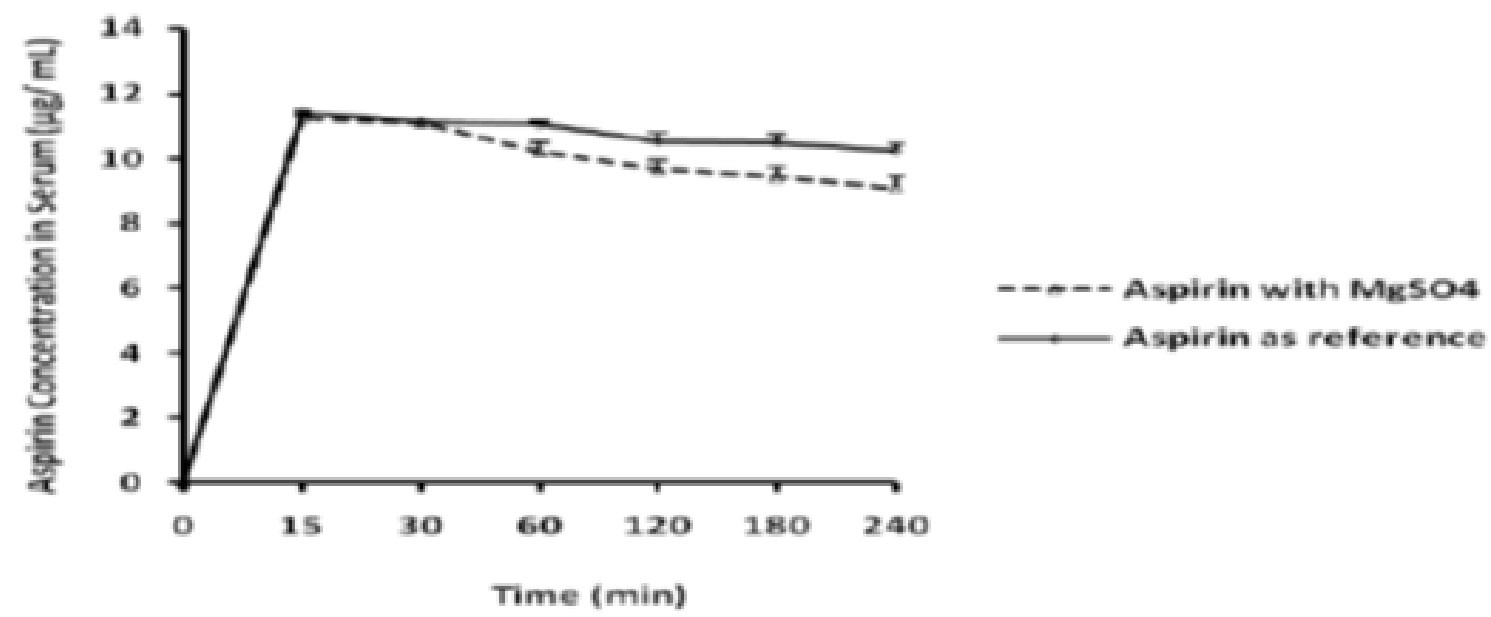

Figure 4: Mean concentration of aspirin vs time curve (both test and reference aspirin).

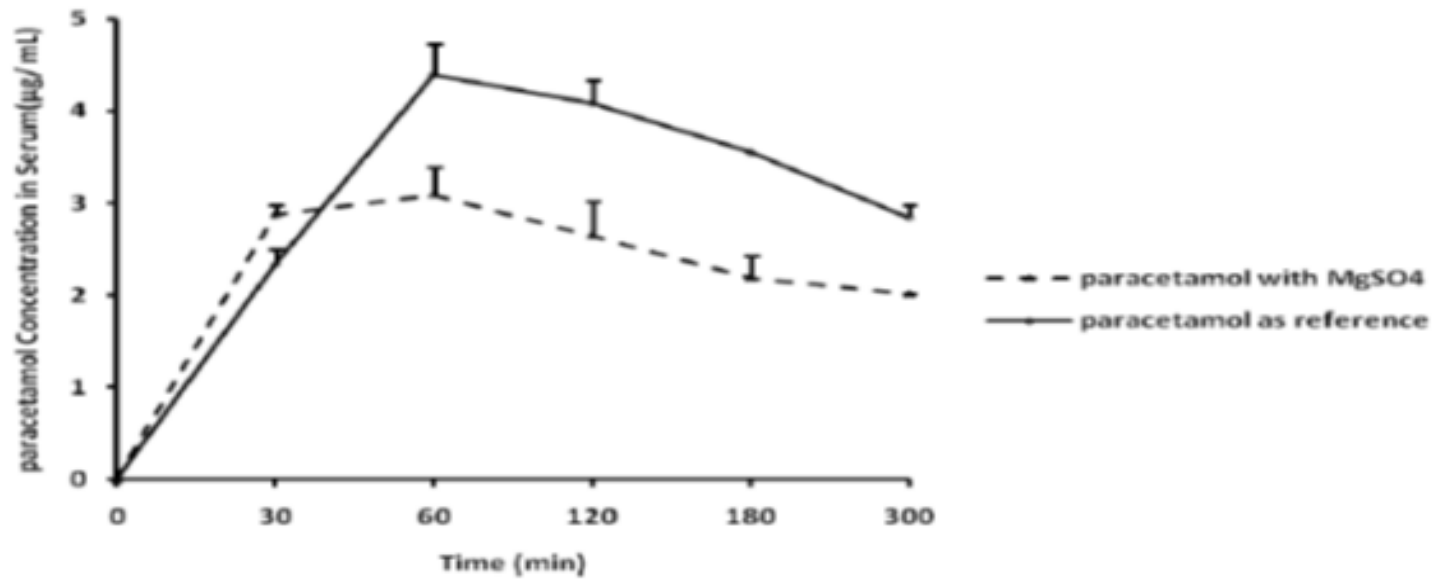

Figure 5: Mean concentration of paracetamol vs time curve (both test and reference).

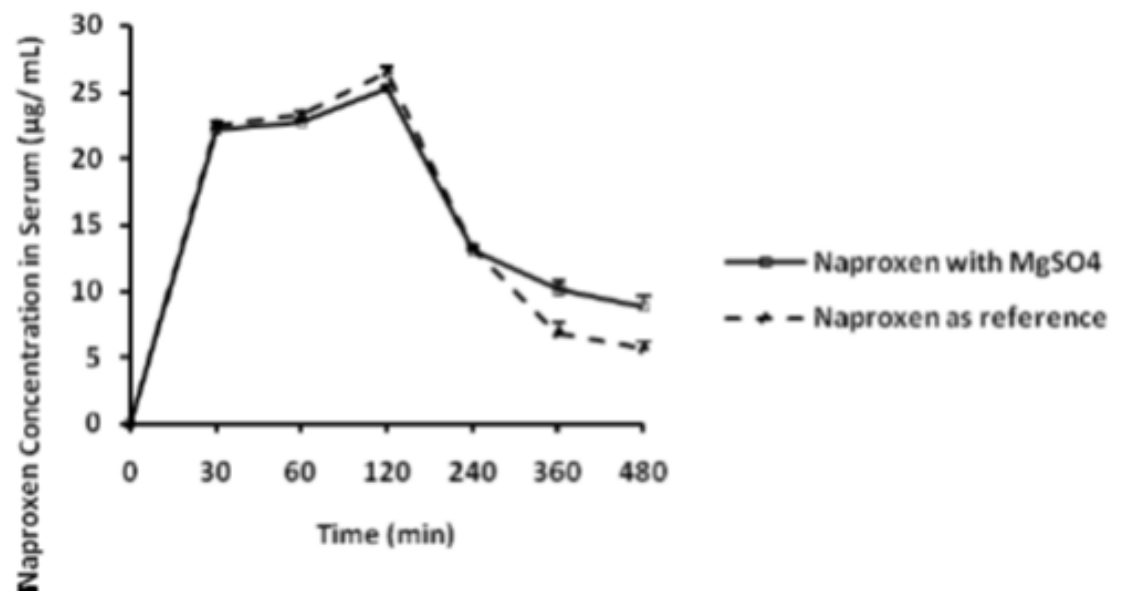

Figure 6: Mean concentration of naproxen vs time curve (both test and reference). 


\begin{tabular}{|c|c|c|c|}
\hline Group & C $_{\max } \pm$ SD & AUC $_{(0-t)} \pm$ SD & AUC \\
\hline Aspirin & \pm SD \\
\hline Aspirin with $\mathrm{MgSO}_{4}$ & $11.39 \pm 0.01$ & $41.37 \pm 0.05$ & $45.05 \pm 0.04$ \\
\hline
\end{tabular}

Table 1: $C_{\max }, A \cup C_{(0-t)}$ and $A \cup C_{(0-\alpha)}$ of test and reference aspirin.

\begin{tabular}{|c|c|c|c|}
\hline Group & $\mathbf{C}_{\max } \pm \mathbf{S D}$ & AUC $_{(0-\mathrm{t})} \pm \mathbf{S D}$ & 10.17 \\
\hline Paracetamol as reference & $4.39 \pm 0.01$ & $16.71 \pm 0.17$ & $22.88 \pm 0.47$ \\
\hline Paracetamol with $\mathrm{MgSO}_{4}$ & $3.09 \pm 0.01$ & $11.72 \pm 0.04$ \\
\hline
\end{tabular}

Table 2: $\mathrm{C}_{\max }, \mathrm{AUC}_{(0-\mathrm{t})}$ and $\mathrm{AUC} \mathrm{C}_{(0-\mathrm{a})}$ of test and reference paracetamol.

\begin{tabular}{|c|c|c|}
\hline Group & $\mathbf{C}_{\max } \pm \mathbf{S D}$ & AUC $_{(0-\mathrm{t})} \pm \mathbf{S D}$ \\
\hline Naproxen as reference & $26.49 \pm 0.01$ & $114.18 \pm 0.14$ \\
\hline Naproxen with $\mathrm{MgSO}_{4}$ & $25.22 \pm 0.01$ & $120.93 \pm 0.01$ \\
\hline
\end{tabular}

Table 3: $\mathrm{C}_{\max }, A \cup \mathrm{C}_{(0-t)}$ and $A \cup C_{(0-\alpha)}$ of test and reference naproxen.

increasing total plasma salicylate concentrations, the unbound fraction increases. Salicylate, in turn, is mainly metabolized by the liver. As mentioned above, aspirin is rapidly biotransformed into the active metabolite, salicylate. Therefore, aspirin has a very short half-life [6]. The relative bioavailability of test aspirin was found $92 \%$ at 240 minutes, considering $\mathrm{AUC}_{0-\mathrm{t}}$ of test and reference aspirin and $92 \%$ after infinitive time, considering $\mathrm{AUC}_{0-\alpha}$ of test and reference aspirin.

As it was known from the absorption profile of aspirin, halflife of this drug is 120 minutes, but in our study aspirin reached the steadystate at 240 minutes. It might be due to insufficient metabolism, increase in protein binding, comperatively high dose of aspirin for both test and reference drug; although from the above study it was found that concurrent administration of magnesiun with aspirin, it slightly increased elimination rate and lower the bioavailability than the reference aspirin.

In human beings, oral paracetamol shows excellent bioavailability. Peak plasma concentrations occur within 30-60 minutes and the $t_{1 / 2}$ in plasma is about $\sim 2$ hour. Binding of the drug to plasma proteins is less in comparison to other NSAIDs [12].

The relative bioavailability of test paracetamol was found to be $70 \%$ at 300 minutes, considering $\mathrm{AUC}_{0-\mathrm{t}}$ of test and reference paracetamol and $70 \%$ after infinitive time (considering $\mathrm{AUC}_{0-a}$ of test and reference paracetamol.

It was also found that concurrent administration of magnesiun with paracetamol markedly increased elimination rate and decreased the bioavailability than that of the reference paracetamol. It might be due to the increased plasma protein binding of paracetamol.

It has been already established that in human being naproxen is absorbed fully when administered orally. Maximum concentrations in plasma occur within 2-4 hour and are somewhat more rapid after the administration of naproxen sodium. Absorption is accelerated by the concurrent administration of sodium bicarbonate but delayed by magnesium oxide or aluminum hydroxide [12]. In our study in rats, the relative bioavailability of test naproxen was found to be $105 \%$ at 480 minutes, considering $\mathrm{AUC}_{0-\mathrm{t}}$ of test and reference naproxen and $112 \%$ after infinitive time, considering $\mathrm{AUC}_{0-\boldsymbol{\alpha} \text { of }}$ test and reference naproxen.

It was observed that while magnesiun was concomitantly administered with naproxen, it decreased elimination rate and remained in systemic circulation for longer time which may be harmful for body or useful in tharapeutic quantities, often avoiding the need of freequent administration.

\section{Conclusion}

From the pharmacokinetic study of aspirin and paracetamol in rats, it was observed that concomitant

administration of magnesium with aspirin, paracetamol and naproxen elimination rate was slighly increased and the bioavailability was lowered the single aspirin or paracetamol. But it was found that concurrent administration of magnesium salt with naproxen not only delayed the absorption rate of naproxen but also decreased its elimination rate and remained in systemic circulation for longer time than the single administered naproxen. The retention of naproxen for longer time in systemic circulation may be harmful for body from tharapeutic consideration. It might be inferred that the combination of NSAID drugs with magnesium might be discouraging or encouraging which can be ascertained only after a longer course of study.

\section{Ethical Approval}

All authors hereby declared that all experiments were performed in accordance with the ethical standards laid down in the Declaration of Helsinki 1964.

\section{Acknowledgement}

Authors are thankful to Professor Dr. Sheikh Nazrul Islam, Institute of Food and Nutrition Sciences (IFNS), University of Dhaka, Bangladesh and the Department of Pharmacy, State University of Bangladesh, Dhanmondi, Dhaka, Bangladesh for their kind permission to use their Animal House and Animal Laboratory.

\section{Competing Interests}

Authors have declared that no competing interests exist.

\section{References}

1. Eds. Gielen and Tiekink (2005) Metallotherapeutic drugs and metal-based diagnostic agents: the use of metals in medicine. John Wiley \& Sons Ltd, 3, pp. 51-61.

2. Ahmad A, Tanvir ZH, Hussain Z. (2010) Acute myocardial infarction; serum magnesium and electrolyte levels at presentation in emergency department. Professional Med J 17(2): 246-251.

3. Stevanovic S, Nikolić M, Stanković A (2011) Dietary magnesium intake and coronary heart disease risk: a study from Serbia, Med Glas Ljek komore Zenicko-doboj kantona 8(2):203-208.

4. Available at http: //www.merckmanuals. com/vet/pharmacology/ant inflammatory_agents/ nonsteroidal_anti-inflammatory_drugs.html. (Date of access: 03 January, 2014).

5. Available at http://sepia.unil.ch/pharmacology /index. php? id=87 (Date of access: 07 January, 2014)

6. Available at http://www.medsafe.govt.nz/profs/datasheet/n/naxentab.pdf (Date of access: 07 January, 2014) 
Citation: Amran S, Koly SF, Kundu SP, Chowdhury AA, Hossain A, et al. (2015) The Pharmacokinetic Study of Aspirin, Paracetamol and Naproxen with Magnesium Sulfate. Pharm Anal Acta 6: 372. doi:10.4172/21532435.1000372

Page 8 of 8

7. Available at http://www.ich.org/fileadmin/Public Web Site/ABOUT ICH/ Organisation/GCC/Topics_under_Harmonisation/Bioequivalence.pdf (Dāte of access: January, 2014)

8. Kundu SP (2014) Comparative Bioavailoability and bioequivalence studies of aceclofenac in human and in rat model, Department of Pharmaceutical Technology, Faculty of Pharmacy, University of Dhaka, Bangladesh, Session 1999- 2000.

9. Wallstein S, Zucker CL, and Fleiss JL (1980) Some statistical methods useful in circulation research. Circ Res 47:1-9.
10. Islam MT, Bhuiyan MAS, Shajiad MMR, Sharif MT, Sultan MZ, Rahman A Hossain MA, Chowdhury AA and Amran MS (2014) A study of prophylactic effect against diabetes of two ayurvedic drugs 'Jambadyarista' and 'Bohumutrantak Ras' in normal as well as alloxan-induced diabetic rats. Brit J Pharm Res 4(16):1945-1955.

11. Saha S, Begum R, Rahman A, Sultan MZ, Amran MS and Hossain MA (2013). Evaluation of in vitro interaction of metformin with ibuprofen in aqueous medium. Bangladesh Pharm J 16(2):189-194.

12. Brunton LL, Parker KL, Blumenthal DK, Buxton ILO (2008) Goodman \& Gilman's Manual of Pharmacology and Therapeutics, McGraw-Hill Companies, New York, USA. pp. 445-452. 